\section{Exploring Melodic Structure to Increase Heterogeneity of Auditory Alarm Sets in Medical Devices}

\author{
Jessica Gillard \\ Michael Schutz \\ McMaster Institute for Music and the Mind \\ McMaster University
}

\section{Background}

Auditory alarms in a medical setting are a useful tool to communicate important information about the status of patients as healthcare professional complete concurrent tasks. To assist device manufacturers and medical staff, the International Electrotechnical Commission (IEC) standardized a set of melodic alarms for eight common medical commands (i.e. the IEC 60601 alarms). Unfortunately, empirical studies of these alarms show they are difficult to learn, hard to remember and are frequently confused [1-3]. Several studies have suggested that these problems may be due to the similarity of IEC alarms insofar as that they have the same length, same rhythm and fall within a narrow pitch range $[2,4]$. Additionally, studies suggest that by increasing the heterogeneity of alarms within a set, learning, memory and discriminability could be improved $[4,5]$. Here we describe an exploratory study in which we looked at multiple factors that could increase heterogeneity. Our initial interest was in amplitude envelope (i.e. the shape of a sound over time), as we have found an improvement in memory associations for sounds with "percussive" (i.e. naturally decaying) envelopes vs. those with "flat" (i.e. artificial-sounding) envelopes in a previous study [6]. This manipulation did not seem to play a role in this context. However, our exploration offers new, detailed information on alarm confusions, insights that can inform future research on alarm design.

\section{Methods}

\section{Experiment 1.}

Participants. Forty-eight undergraduate students participated in the study for course credit.

Apparatus \& Stimuli. We selected eight tone sequences used in a previous study [6]; each consisting of a $4 \mathrm{~s}$ sound file containing four pure tones. Although we manipulated the temporal structure of the tones, we ultimately collapsed across envelope type to obtain maximum power for the confusion data (details on the temporal structure of sounds used can be found in [6[]). We labeled each tone sequence with a number from 1-8 (Table 1) and presented them over headphones at a comfortable listening level, held constant for all participants. Participants also filled out a questionnaire regarding demographics and musical training.

Procedure. We asked participants to imagine themselves as a surgeon and explained the task was to learn to identify eight medical alarms. We gave participants a list of the alarm commands and defined their meaning. The experiment consisted of 4 phases: Familiarization, Training, Break and Evaluation, and we randomized the pairings of tone sequences and alarm commands for each participant.

Familiarization Phase - We played each of the eight tone sequences twice (sequentially) in a random order and informed participants of the correct alarm association. Participants heard a 'soothing sound' (i.e. a 6s burst of white noise) between different tone sequence presentations to ensure even spacing between trials.

Training Phase - Upon hearing a tone sequence, participants were asked to identify the correct alarm association. We gave the participant feedback on their correctness, replayed the tone sequence and informed the participant of the correct alarm association regardless of their answer. We did this in a random order for all eight alarms, which made up a block of training. These blocks repeated until participants could correctly identify $7 / 8$ alarms in 2 consecutive blocks or reached a maximum of 10 blocks.

Break - After the Training Phase, participants performed a distracter task (an online mini golf game loaded from http://www .addictinggames.com/sports-games/miniputt3.jsp). We turned off the sound to ensure the distracter task did not interfere with our evaluation of alarm learning and retention.

Evaluation Phase - Participants heard each tone sequence and were asked the to identify the correct alarm association as well as their confidence of their answer on a scale form 1 (Not confident at all) to 6 (Very confident). Participants did not receive feedback during this phase, but received a final score upon completion.

\section{Experiment 2.}

Participants. Forty undergraduate students participated in the study for course credit.

Apparatus \& Stimuli. Stimuli consisted of the eight standardized IEC 60601 alarms (Table 1). All other aspects were the same as in Exp. 1.

Procedure. The procedure was identical to that of Exp. 1 except we maintained the alarm-command pairings, as opposed to randomizing them as we did in Exp 1.

\section{Results}

\begin{tabular}{|c|c|c|c|}
\hline \multicolumn{2}{|r|}{ Experiment 1 } & \multicolumn{2}{|r|}{ Experiment 2} \\
\hline Alarm & Notes & Alarm & Notes \\
\hline 1 (Red) & $277 \mathrm{~Hz}-294 \mathrm{~Hz}-415 \mathrm{~Hz}-392 \mathrm{~Hz}(\mathrm{C} \# 4-\mathrm{D} 4-\mathrm{G} \# 4-\mathrm{G} 4)$ & Oxygen (Red) & $523 \mathrm{~Hz}-466 \mathrm{~Hz}-440 \mathrm{~Hz}(\mathrm{C} 5-\mathrm{B} 4-\mathrm{A} 4)$ \\
\hline 2 (Orange) & $440 \mathrm{~Hz}-330 \mathrm{~Hz}-440 \mathrm{~Hz}-220 \mathrm{~Hz}(\mathrm{~A} 4-\mathrm{E} 4-\mathrm{A} 4-\mathrm{A} 3)$ & Ventilation (Orange) & $262 \mathrm{~Hz}-440 \mathrm{~Hz}-349 \mathrm{~Hz}(\mathrm{C} 4-\mathrm{A} 4-\mathrm{F} 4)$ \\
\hline 3 (Olive) & $349 \mathrm{~Hz}-440 \mathrm{~Hz}-262 \mathrm{~Hz}-233 \mathrm{~Hz}(\mathrm{~F} 4-\mathrm{A} 4-\mathrm{C} 4-\mathrm{A} \# 3)$ & Temperature (Olive) & $262 \mathrm{~Hz}-294 \mathrm{~Hz}-330 \mathrm{~Hz}(\mathrm{C} 4-\mathrm{D} 4-\mathrm{E} 4)$ \\
\hline 4 (Green) & $415 \mathrm{~Hz}-392 \mathrm{~Hz}-370 \mathrm{~Hz}-415 \mathrm{~Hz}(\mathrm{G} \# 4-\mathrm{G} 4-\mathrm{F} \# 4-\mathrm{G} \# 4)$ & General (Green) & $262 \mathrm{~Hz}-262 \mathrm{~Hz}-262 \mathrm{~Hz}(\mathrm{C} 4-\mathrm{C} 4-\mathrm{C} 4)$ \\
\hline 5 (Cyan) & $370 \mathrm{~Hz}-349 \mathrm{~Hz}-330 \mathrm{~Hz}-311 \mathrm{~Hz}(\mathrm{~F} \# 4-\mathrm{F} 4-\mathrm{E} 4-\mathrm{D} \# 4)$ & Power Failure (Cyan) & $523 \mathrm{~Hz}-262 \mathrm{~Hz}-262 \mathrm{~Hz}(\mathrm{C} 5-\mathrm{C} 4-\mathrm{C} 4)$ \\
\hline 6 (Blue) & $220 \mathrm{~Hz}-440 \mathrm{~Hz}-330 \mathrm{~Hz}-294 \mathrm{~Hz}(\mathrm{~A} 4-\mathrm{A} 3-\mathrm{E} 4-\mathrm{D} 4)$ & Cardiovascular (Blue) & $262 \mathrm{~Hz}-330 \mathrm{~Hz}-392 \mathrm{~Hz}(\mathrm{C} 4-\mathrm{E} 4-\mathrm{G} 4)$ \\
\hline 7 (Purple) & $440 \mathrm{~Hz}-330 \mathrm{~Hz}-349 \mathrm{~Hz}-220 \mathrm{~Hz}(\mathrm{~A} 4-\mathrm{E} 4-\mathrm{F} 4-\mathrm{A} 3)$ & Perfusion (Purple) & $262 \mathrm{~Hz}-370 \mathrm{~Hz}-262 \mathrm{~Hz}(\mathrm{C} 4-\mathrm{F} \# 4-\mathrm{C} 4)$ \\
\hline 8 (Pink) & $220 \mathrm{~Hz}-247 \mathrm{~Hz}-294 \mathrm{~Hz}-294 \mathrm{~Hz}(\mathrm{~A} 3-\mathrm{B} 3-\mathrm{D} 4-\mathrm{D} 4)$ & Infusion (Pink) & $523 \mathrm{~Hz}-294 \mathrm{~Hz}-392 \mathrm{~Hz}(\mathrm{C} 5-\mathrm{D} 4-\mathrm{G} 4)$ \\
\hline
\end{tabular}

Table 1 - Summary of the pitches used in the tone sequences in Experiment 1 and 2. 

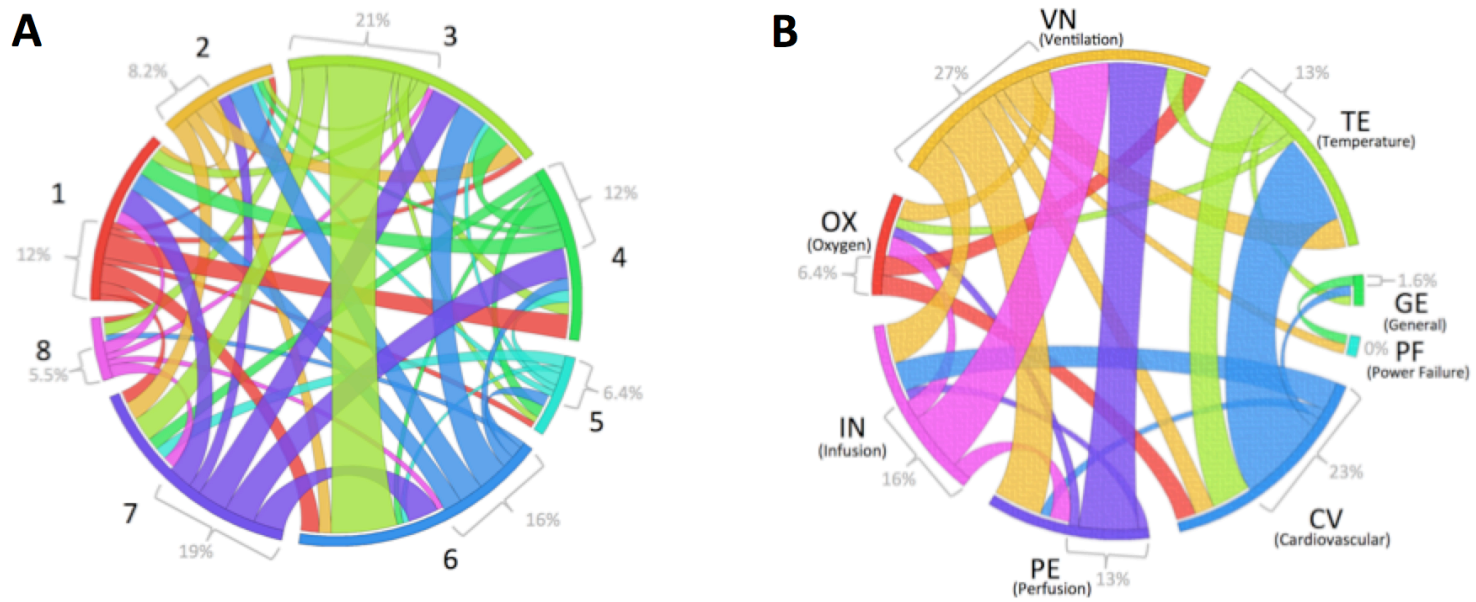

Figure 1 - Alarm Confusion in the Evaluation Phase for (A) Experiment 1 and (B) Experiment 2. Thicker segments around the circumference of the circle and bands spanning from segment to segment indicate higher rates of confusion.

\section{Experiment 1.}

The pattern of confusions (i.e. when one alarm was 'confused' with another) in the Evaluation phase is plotted in Fig 1a. The plot depicts total confusions $(n=109)$ around the circumference of the circle, with each of the eight alarms represented by different coloured segments. Alarms 3 (Olive), 6 (Blue), and 7 (Purple) were the most highly confused, representing $21 \%(n=23), 16 \%(n=17)$ and $19 \%(n=21)$ of total confusions respectively. Moderately confused alarms include 1 (Red) and 4 (Green) representing 12\% ( $\mathrm{n}=13)$ of total confusions each. Mildly confused alarms include 2 (Orange), 5 (Cyan) and 8 (Pink) representing 8.3\% ( $\mathrm{n}=9)$, $6.4 \%(n=7)$ and $5.5 \%(n=6)$ of total confusions respectively.

\section{Experiment 2}

The pattern of confusions in the Evaluation phase is plotted in Fig 1b. Again, the plot depicts total confusions $(n=62)$ around the circumference with each alarm represented by different segments. The Ventilation (Orange) and Cardiovascular alarms (Purple) were the most highly confused, representing $27 \% \quad(n=17)$ and $23 \% \quad(n=14)$ respectively. Moderately confused alarms include Temperature (Olive), Perfusion (Blue) and Infusion (Pink), accounting for $13 \%(n=8), 13 \%(n=8)$ and $16 \%(n=10)$ of total confusions respectively. The Oxygen (Red) and General alarms (Green) were mildly confused, accounting for only $6.4 \%(n=4)$ and $1.6 \%(n=1)$ of total confusions respectively. The Power Failure alarm was not confused at all $(n=0)$.

\section{Interpretation}

The most highly confused alarms in both experiments consisted of those with highly similar contours (i.e. alarms 3 and 6 in Exp. 1 as well as the Temperature and Cardiovascular alarms in Exp. 2). However, other alarms sharing similarities in contour were not as highly confused providing they had at least one distinctive feature between them. For example, alarms 2 and 7 in Exp. 1 have a similar overall contour of a descending interval followed by an ascending interval and a descending interval, but were not highly confused. This might be due to the fact that alarm 2 contains a repeated note, making it more distinct than alarm 7. Additionally, alarms with distinct features were the least confused. This can be seen in alarms containing repeated notes (i.e. alarms 2 and 8 in Exp. 1 and the General and Power
Failure alarms in Exp. 2) as well as those with distinct contours (i.e. alarm 5 in Exp. 1 and the Oxygen alarm in Exp. 2 both have a continuous falling contour, unlike other alarms in the set). Lastly, alarms that have contours that change direction seem to be frequently confused with each other, suggesting they might be cognitively grouped together.

These finding suggest that careful consideration of an alarm's melodic structure might help increase heterogeneity over and above other efforts discussed previously such as varying timbre and rhythm [4,5]. Such improvements might ultimately reduce many document problems with the current alarms [1-3], thereby improving patient care.

\section{References}

[1] Lacherez, P., Seah, E. L., \& Sanderson, P. M., 2007, "Overlapping Melodic Alarms Are Almost Indiscriminable," Human Factors, 49(4), pp. 637-645.

[2] Sanderson, P. M., Wee, A. N., \& Lacherez, P., 2006, "Learnability and Discriminability of Melodic Medical Equipment Alarms," Anaesthesia, 61(2), pp. 142-147.

[3] Wee, A. N., \& Sanderson, P. M., 2008, "Are Melodic Medical Equipment Alarms Easily Learned?," Anesthesia \& Analgesia, 106(2), pp. 501-508.

[4] Edworthy, J., \& Hellier, E., 2006, "Alarms and Human Behaviour: Implications For Medical Alarms," British Journal of Anaesthesia, 97(1), pp. 12-17.

[5] Edworthy, J., Hellier, E., Titchener, K., Naweed, A., \& Roels, R., 2011, "Heterogeneity in Auditory Alarm Sets Makes Them Easier to Learn," International Journal of Industrial Ergonomics, 41(2), pp. 136-146.

[6] Schutz, M., \& Stefanucci, J. K., 2010, “Amplitude Envelope and Auditory Alarms," Proc. International Conference of Music Perception and Cognition. Seattle, WA

\section{Acknowledgements}

We would like to acknowledge financial assistance for this research through grants to Dr. Michael Schutz from the Natural Sciences and Engineering Research Council of Canada (NSERC RGPIN/386603-2010), Ontario Early Researcher Award (ER10-07-195) and the Canadian Foundation for Innovation (CFI-LOF 30101). 